\section{Regards sur l'économie allemande}

Bulletin économique du CIRAC

98-99 | 2010

Varia

\title{
L'Allemagne unie, une Allemagne de notre confiance
}

René Lasserre

\section{(2) OpenEdition}

1 Journals

Édition électronique

URL : http://journals.openedition.org/rea/4171

DOI : 10.4000/rea.4171

ISBN : 978-2-8218-0892-8

ISSN : 1965-0787

\section{Éditeur}

CIRAC

Édition imprimée

Date de publication : 26 octobre 2010

Pagination : 1-2

ISSN : 1156-8992

Référence électronique

René Lasserre, «L'Allemagne unie, une Allemagne de notre confiance », Regards sur l'économie

allemande [En ligne], 98-99 | octobre 2010, mis en ligne le 05 novembre 2010, consulté le 21 décembre 2020. URL : http://journals.openedition.org/rea/4171 ; DOI : https://doi.org/10.4000/rea.4171 


\title{
L'Allemagne unie, une Allemagne de notre confiance
}

\begin{abstract}
Alors que l'on célèbre en Europe le $20^{\mathrm{e}}$ anniversaire de l'unité allemande retrouvée et que l'on se félicite d'une réussite certes inachevée mais incontestable au regard de l'ampleur des défis à surmonter, on ne peut oublier le message lucide et généreux que Joseph Rovan avait lancé dès octobre 1945 dans la revue Esprit, au lendemain de l'effondrement du nazisme. Devant le spectacle atterrant d'une Allemagne en ruines, moralement détruite et politiquement anéantie, Joseph Rovan invoquait "l'Allemagne de nos mérites", exhortant les Français à œuvrer à la reconstruction d'une Allemagne démocratique au cœur d'une Europe réconciliée.
\end{abstract}

En cela, il traçait une perspective à la fois exigeante et visionnaire à laquelle les artisans de la coopération européenne ont su donner corps et à laquelle l'Histoire a progressivement donné raison, en dépit de la longue et douloureuse épreuve que furent la division de l'Europe et de l'Allemagne. Pleinement associée au projet européen, la République fédérale y joua magistralement sa partition, par la vitalité de son renouveau démocratique, les performances de son modèle économique et social, son engagement à faire prévaloir la volonté conjointe des européens pour faire face à leurs défis communs, sans oublier son souci d'entretenir le dialogue avec l'Est. Autant de champs d'action où, la main dans la main avec ses partenaires européens et occidentaux, elle contribua efficacement à affirmer l'ascendance de la démocratie libérale sur le socialisme totalitaire et à précipiter l'implosion de celui-ci.

La chute du Mur de Berlin et celle du communisme ont cependant bouleversé les équilibres de l'Europe, au risque de mettre la solidarité européenne en péril et d'ouvrir la voie à un retour en force des nationalismes. L'enclenchement rapide du processus d'unification de l'Allemagne et les conditions de sa prise en main par le gouvernement de la République fédérale ont fait immédiatement resurgir chez les partenaires de cette dernière le spectre de la puissance et de l'hégémonie allemandes. Le couple francoallemand en particulier, symbolisé par le tandem Kohl-Mitterrand, fut soumis initialement à rude épreuve. Mais assez vite prévalut entre les deux hommes l'engagement réciproque selon lequel l'unification politique de l'Allemagne s'inscrirait pleinement dans une nouvelle étape décisive de l'intégration européenne. Et ce, en instaurant une souveraineté et une responsabilité économiques partagées de l'Allemagne et de ses partenaires au sein de l'Union économique et monétaire européenne. C'est dès lors dans le cadre de cette volonté commune qui trouvera son expression dans le Traité de Maastricht de 1992 et du processus de convergence économique progressive de l'UEM qu'évolueront désormais la politique économique de l'Allemagne unifiée et de ses principaux partenaires et que naîtra l'Euro, l'avancée la plus marquante et plus que jamais essentielle de l'intégration européenne.

La priorité donnée à l'élargissement progressif de l'Union aux nouvelles démocraties d'Europe centrale procéda d'une nécessité politique incontournable, mais constitua une nouvelle rupture d'équilibre qui eut pour effet de rendre plus difficile l'approfondissement de la coopération institutionnelle 
entre les Etats fondateurs et de distendre les mécanismes de coopération existants. L'élargissement offrit ainsi une échappatoire facile à une intégration plus poussée. Les réticences de la France à consentir de nouveaux transferts de souveraineté au-delà d'une union monétaire de plus en plus ressentie comme trop contraignante se traduiront par une fin de non recevoir opposée aux propositions allemandes d'une coopération politique renforcée. Conjuguées par la suite à la pusillanimité réformatrice du premier gouvernement Schröder, elles conduiront à l'asphyxie progressive du moteur franco-allemand avant de culminer en 2005 dans le rejet du Traité constitutionnel, hypothéquant ainsi durablement le processus de l'union politique. Mais pendant toute cette période qui coïncida avec la présidence Chirac, l'opting-out français ne fut pas uniquement dommageable à la construction de l'Europe, mais aussi à la France elle-même, puisque le nonrespect délibéré des disciplines budgétaires du Pacte de stabilité, alors même que le pays connaissait une période de croissance favorable, allait gravement obérer ses marges de manœuvre futures face à la crise. Quant à la politique qui, depuis 2007 , persiste à vouloir fonder le retour de la croissance sur une demande financée par le déficit, il est désormais patent qu'elle ne conduit qu'au décrochage et qu'elle impose un changement de cap, certes annoncé mais pas encore effectif.

Au début des années 2000, l'Allemagne quant à elle se voit confrontée à une crise de compétitivité sans précédent où se conjuguent les effets d'une conjoncture mondiale récessive et l'accumulation des charges considérables héritées de l'unification. Alors que les déficits et la dette se creusent, le chômage explose et franchit la barre inquiétante des 5 millions tandis que l'économie s'enlise dans le marasme. Le pays ne peut alors échapper à une cure sévère d'assainissement budgétaire et de restructuration de ses régimes sociaux qu'engage le second gouvernement Schröder en 2003 avec l'Agenda 2010, et qui sera poursuivie avec détermination par la Grande coalition CDU-SPD sous la direction d'Angela Merkel. L'Allemagne sera au rendez-vous de la reprise mondiale dès 2006, elle renoue avec la compétitivité et la croissance en même temps qu'elle opère un spectaculaire redressement de ses comptes publics et sociaux. Ces performances ont lui ont permis d'affronter et de surmonter le choc de 2008-2009 dans des conditions qui se révèlent aujourd'hui optimales. Mais aussi, quoi qu'on ait pu en dire et redire de ce côté du Rhin, de faire apparaître l'Allemagne à la fois comme le véritable garant de l'Euro, et maintenant comme le principal moteur de la reprise sur le marché européen. Entre la France et l'Allemagne unie, le fossé n'a cessé ces dernières années de se creuser, dans les mots comme dans les faits.

Le bilan rétrospectif que, dans ce numéro spécial, nous présentons de 20 ans d'unité allemande dans quelques domaines significatifs, vient à point nommé pour souligner combien, dans la gestion de cet immense chantier et de cette épreuve sans pareille que fut l'unification, notre voisin et partenaire a su, pour reprendre l'aphorisme mémorable de Joseph Rovan, se montrer à la hauteur de notre confiance. L'unité allemande a largement confirmé nos attentes et nos espoirs de voir enfin à nos portes un peuple allemand à nouveau réuni, délivré de ses murs et tranquille dans ses frontières, riche de sa diversité et de ses identités plurielles, à la fois solidaire et pleinement réconcilié avec lui-même. D'avoir à nos côtés un partenaire prospère plus soucieux d'équilibre et de performance durable que de puissance. D'avoir la chance de pouvoir nous appuyer sur un acteur responsable, qui sait courageusement regarder la réalité en face, et qui dans le jeu communautaire, s'attache à définir des règles communes et mettre en œuvre les choix qui s'imposent, à la fois pour lui-même et ses partenaires.

C'est le cour et la raison qui nous le disent : nous n'avons pas d'alternative à la convergence franco-allemande.

René Lasserre, le 22 octobre 2010 